\title{
KONSEP PERAN KELUARGA DALAM PENCEGAHAN ADVERSE EVENTS PADA PENYAKIT MENULAR
}

\author{
EMYRANDA SAMOSIR
}

\author{
emyrandasamosir@gmail.com
}

\begin{abstract}
Penyakit Menular menjadi penyumbang yang mendominasi angka kematian di Indonesia.Penyakit menular adalah penyakit yang disebabkan oleh transmisi infectius agent/produk toksinnya dari seseorang/reservoir ke orang lain/susceptable host.Pertumbuhan penyakit ini memesat akibat penularan antar pasien,pelayan kesehatan dan keluarga.Perlu adanya penerapan patient safety.Program patient safety diperankan oleh pasien,perawat dan keluarga.Keluarga sebagai partner dalam pelayanan kesehatan harus mampu bekerja sama secara secara optimal dengan perawat untuk dapat memutus rantai penularan penyakit sebagai insiden Kejadian Tidak Diharapkan(Adverse Events). Penerapan model pemberdayaan berbasis keluarga : family-centered nursing merupakan teori keperawatan dengan asuhan keperawatan dengan pendekatan proses keperawatan dengan sistem keperawatan pendidikan kesehatan, coaching dan peereducation. Merupakan salah satu intervensi keperawatan yang mendukung pelaksanaan tugas kesehatan keluarga dalam pencegahan penularan penyakit menular. Perhatian dan empati terhadap stressor dan penggobatan yang dijalani pasien akan membuat seseorang merasa lebih dihargai dan memepengaruhi tingkah laku,meningkatkan kesejahteraan psikologis,serta dapat menggurangi konsekuensi negatif dari stress yang dapat meningkatkan prevalensi kekambuhan penyakit menular.Kajian ini berfokus pada pentingnya peran keluarga dalam penyembuhan sekaligus pemutusan rantai penularan penyakit .Konsep peran keluarga dibangun guna memaksimalkan pelayanan kesehatan.
\end{abstract}

Kata Kunci : Patient Safety,Peran Keluarga,Kejadian Tidak Diharapkan,Adverse Events 


\section{LATAR BELAKANG}

Menurut Natoadmodjo

Penyakit menular adalah penyakit yang dapat ditularkan (berpindah dari orang yang satu ke orang yang lain, baik secara langsung maupun melalui perantara). Penyakit Menular [comunicable Diseasse] adalah penyakit yang disebabkan oleh transmisi infectius agent/produk toksinnya dari seseorang/reservoir ke orang lain/susceptable host.Contoh-contoh dari penyakit menular ialah $\mathrm{TB}$ Paru,Malaria,HIV/AIDS,SARS,Ebola,H1 N1,MERS-CoV,difteri,TB RO,Rabies dan lain-lain.

Penyakit menular dapat disebabkan oleh banyak faktor,salah satunya ialah Pelayanan Kesehatan. Pelayanan menyeluruh kesehatan adalah suatu bagian sistem pelayanan kesehatan yang memiliki tujuan utamanya yaitu sebagai suatu sistem yang memberikan pencegahan secara dini dan sebagai suatu sistem yang memberikan promosi kesehatan untuk melakukan perubahan derajat kesehatan masyarakat (Notoatmodjo, 2010).Dalam pelayanan kesehatan ada banyak peran-peran yang turut ambil bagian didalamnya seperti Perawat,Pasien,Keluarga dan Lingkungan.Peran tersebut harus dapat bekerja sama untuk memaksimalkan pelayanan kesehatan sekaligus memutus rantai penularan penyakit .
Patient Safety atau keselamatan pasien merupakan isu global yang mempengaruhi negara-negara di semua tingkat pembangunan. Meskipun perkiraan ukuran permasalahan masih belum pasti,khususnya di negara berkembang dan negara transisi/konflik, ada kemungkinan bahwa jutaan pasien seluruh dunia menderita cacat, cedera atau meninggal setiap tahun karena pelayanan kesehatan yang tidak aman. Insiden dipelayanan kesehatan meliputi Kondisi Potensial Cedera(KPC),Kejadian Nyaris Cedera (KNC),Kejadian Tidak Cedera (KTC),Kejadian Tidak Diharapkan(KTD).

Penularan Penyakit melalui pelayanan kesehatan termasuk kedalam insiden pelayanan kesehatan yaitu kejadian yang tidak diharapkan (KTD) atau Adverse Events.Pada kondisi ini bukan hanya peran perawat yang menjadi faktor penularannya melainkan peran keluarga juga ikut ambil bagian.

\section{TUJUAN}

Tujuan dari patient safety pada pelayanan kesehatan ialah

1.Terciptanya budaya keselamatan pasien

2.Meningkatnya akuntabilitas rumah sakit terhadap pasien dan masyarakat

3.Menurunnya KTD dirumah sakit 
4.Terlaksananya program-program pencegahan sehingga tidak terjadi pengulanggan KTD.

Tujuan dari kajian ini ialah untuk memaparkan konsep peran keluarga sebagai partner dalam pelayanan kesehatan untuk menurunkan insiden KTD (adverse events)dalam mencegahan penularan penyakit demi memaksimalkan pelayanan kesehatan.

\section{METODE}

Rancangan penugasan kajian ini menggunakan literature review berdasarkan jurnal,dan e-book (yang dipublikasikan 10 tahun terakhir) dan menggunakan dua belas sumber referensi dengan menganalisis, eksplorasi, dan kajian bebas sesuai dengan judul penugasan kajian ini.

\section{HASIL}

Melalui hasil literature review dari jurnal,ebookdan karya ilmiah lainnya dapat disimpulkan Penyakit Menular [comunicable Diseasse] adalah penyakit yang disebabkan oleh transmisi infectius agent/produk toksinnya dari seseorang/reservoir ke orang lain/susceptable host.

Segitiga epidemiologi (trias epidemiologi) merupakan konsep dasar dalam epidemiologi yang menggambarkan hubungan antara tiga faktor utama yang berperan dalam terjadinya penyakit atau masalah kesehatan yaitu host (tuan rumah/penjamu), agen (penyebab), dan environtment. Timbulnya penyakit terjadi akibat ketidak seimbangan ketiga faktor tersebut. Untuk menjaga keseimbangan faktor tesebut dibutuhkan upaya patient safety yang dilakukan oleh pasien,perawat dan keluarga yang saling berkerjasama .Upaya ini bertujuan untuk menggurangi prevalensi kekambuhan pasien dan pemutusan rantai penularan penyakit pasien sebagai pencegahan insiden Kejadian Tidak Diharapkan (Adverse Events).Terdapat Tujuh Standar Keselamatan Pasien (mengacu pada "Hospital Patient Safety Standards" yang dikeluarkan oleh Joint Commision on Accreditation of Health Organizations, Illinois, USA, tahun 2002),yaitu:Hak Pasien,Mendidik Pasien dan Keluarga,Keselamatan pasien dan kesinambungan pelayanan, Penggunaan metode-metode peningkatan kinerja untuk melakukan evaluasi dan program peningkatan keselamatan pasien, Peran kepemimpinan dalam meningkatkan keselamatan pasien,Mendidik staf tentang keselamatan pasien,dan Komunikasi 
merupakan kunci bagi staf untuk mencapai keselamatan pasien.Peran keluarga juga memiliki pengaruh yang sangat besar terhadap patient safety. Peran keluarga dalam memberikan dukungan emosional,penghargaan,informasi dan instrumental sangat penting guna memberikan rasa lebih dihargai dan memepengaruhi tingkah

laku,meningkatkan kesejahteraan psikologis,serta dapat menggurangi konsekuensi negatif dari stress yang dapat meningkatkan prevalensi kekambuhan penyakit menular pada pasien

\section{PEMBAHASAN}

Penyakit menular dapat berpindah satu tempat ke tempat yang lain. Perpindahan ini bisa terjadi dengan sangat cepat sehingga berkembang menjadi wabah atau endemis pada daerah tertentu. Ada beberapa cara perpindahan penyakit menular pertama perpindahan penyakit secara langsung yang merupakan proses berpindahnya penyakit dari manusia 1 ke manusia lain secara langsung tanpa perantara, misalnya: penularan melalui tetesan-tetesan halus yang terhambur dari manusia yang sakit seperti ludah, bersin pada penyakit TBC. Model perpindahan ke dua adalah Penularan secara tidak langsung, Merupakan proses pemindahan penyakit melalui perantara. Perantara tersebut bisa dari golongan bakteri, serangga, serta bisa dari kotoran. Misalnya kolera, disentri dan demam berdarah dengue.

Aspek sentral penyebaran penyakit menular dalam masyarakat adalah mekanisime penularan (mode of transmissions) yakni berbagai mekanisme di mana unsur penyebab penyakit dapat mencapai manusia sebagai penjamu yang potensial. Mekanisme tersebut meliputi cara unsur penyebab (agent) meninggalkan reservoir, cara penularan untuk mencapai penjamu potensial, serta cara masuknya ke penjamu potensial tersebut. Seseorang yang sehat sebagai salah seorang penjamu potensial dalam masyarakat, mungkin akan ketularan suatu penyakit menular tertentu sesuai dengan posisinya dalam masyarakat serta dalam pengaruh berbagai reservoir yang ada di sekitarnya. Kemungkinan tersebut sangat di pengaruhi pula olah berbagai faktor antara lain: a). Faktor lingkungan fisik sekitarnya yang merupakan media yang ikut mempengaruhi kualitas maupun kuantitas unsur penyebab. b). Faktor lingkungan biologis yang menentukan jenis vektor dan resevoir penyakit serta unsur biologis yang hidup berada di sekitar manusia. c). Faktor lingkungan sosial yakni kedudukan setiap orang dalam masyarakat, termasuk kebiasaan hidup serta kegiatan sehari-hari. 
Upaya "Patient Safety " dalam pelayanan kesehatan masih perlu ditingkatkan secara maksimal demi mencapai visi misi pelayanan kesehatan.Tak jarang insiden pelayanan kesehatan mengakibatkan kerugian bagi pasien,pelayan kesehatan serta keluarga.Salah satu insiden tersebut ialah Kejadian Tak diharapkan(Adverse Events) yang merupakan suatu kejadian yang mengakibatkan cedera yang tidak diharapkan pada pasien karena suatu tindakan (commision) atau tidak mengambil tindaklan yang seharusnya diambil (omission) dan bukan karena "underlying disease"atau kondisi pasien.

Tujuh Standar Keselamatan Pasien (mengacu pada "Hospital Patient Safety Standards" yang dikeluarkan oleh Joint Commision on Accreditation of Health Organizations, Illinois, USA, tahun 2002),yaitu:

\section{Hak pasien}

Standarnya adalah Pasien \& keluarganya mempunyai hak untuk mendapatkan informasi tentang rencana \& hasil pelayanan termasuk kemungkinan terjadinya KTD (Kejadian Tidak Diharapkan).

\section{Kriterianya :}

1) Harus ada dokter penanggung jawab pelayanan
2) Dokter penanggung jawab pelayanan wajib membuat rencana pelayanan

3) Dokter penanggung jawab pelayanan wajib memberikan penjelasan yang jelas dan benar kepada pasien dan keluarga tentang rencana dan hasil pelayanan, pengobatan atau prosedur untuk pasien termasuk kemungkinan terjadinya KTD

2. Mendidik pasien dan keluarga

Standarnya adalah RS harus mendidik pasien \& keluarganya tentang kewajiban \& tanggung jawab pasien dalam asuhan pasien.

\section{Kriterianya :}

Keselamatan dalam pemberian pelayanan dapat ditingkatkan dengan keterlibatan pasien adalah partner dalam proses pelayanan. Karena itu, di RS harus ada system dan mekanisme mendidik pasien \& keluarganya tentang kewajiban \& tanggung jawab pasien dalam asuhan pasien.Dengan pendidikan tersebut diharapkan pasien \& keluarga dapat:

1) Memberikan info yg benar, jelas, lengkap dan jujur

2) Mengetahui kewajiban dan tanggung jawab

3) Mengajukan pertanyaan untuk hal yg tdk dimengerti 
4) Memahami dan menerima konsekuensi pelayanan

5) Mematuhi instruksi dan menghormati peraturan RS

6) Memperlihatkan sikap menghormati dan tenggang rasa

7) Memenuhi kewajiban finansial yang disepakati

3. Keselamatan pasien dan kesinambungan pelayanan

Standarnya adalah RS menjamin kesinambungan pelayanan dan menjamin koordinasi antar tenaga dan antar unit pelayanan.

\section{Kriterianya :}

1) koordinasi pelayanan secara menyeluruh

2) koordinasi pelayanan disesuaikan kebutuhan pasien dan kelayakan sumber daya

3)koordinasi pelayanan mencakup peningkatan komunikasi

4)komunikasi dan transfer informasi antar profesi kesehatan

4.Penggunaan metode-metode peningkatan kinerja untuk melakukan evaluasi dan program peningkatan keselamatan pasien

Standarnya adalah RS harus mendesign proses baru atau memperbaiki proses yg ada, memonitor \& mengevaluasi kinerja melalui pengumpulan data, menganalisis secara intensif KTD, \& melakukan perubahan untuk meningkatkan kinerja serta KP.

\section{Kriterianya :}

1)Setiap rumah sakit harus melakukan proses perancangan (design) yang baik, sesuai dengan "Tujuh Langkah Menuju Keselamatan Pasien Rumah Sakit”.

2)Setiap rumah sakit harus melakukan pengumpulan data kinerja

3)Setiap rumah sakit harus melakukan evaluasi intensif

4) Setiap rumah sakit harus menggunakan semua data dan informasi hasil analisis

5.Peran kepemimpinan dalam meningkatkan keselamatan pasien

1) Pimpinan dorong $\&$ jamin implementasi progr KP melalui penerapan "7 Langkah Menuju KP RS ”.

2)Pimpinan menjamin berlangsungnya program proaktif identifikasi risiko KP \& program mengurangi KTD.

3)Pimpinan dorong \& tumbuhkan komunikasi \& koordinasi antar unit \& individu berkaitan dengan pengambilan keputusan tentang KP

4) Pimpinan mengalokasikan sumber daya yg adekuat utk mengukur, mengkaji, \& 
meningkatkan kinerja RS serta tingkatkan KP.

5.Pimpinan mengukur \& mengkaji efektifitas kontribusinyadalam meningkatkan kinerja RS \& KP.

\section{Kriterianya :}

1)Terdapat tim antar disiplin untuk mengelola program keselamatan pasien.

2)Tersedia program proaktif untuk identifikasi risiko keselamatan dan program meminimalkan insiden,

3)Tersedia mekanisme kerja untuk menjamin bahwa semua komponen dari rumah sakit terintegrasi dan berpartisipasi

4)Tersedia prosedur "cepat-tanggap" terhadap insiden, termasuk asuhan kepada pasien yang terkena musibah, membatasi risiko pada orang lain dan penyampaian informasi yang benar dan jelas untuk keperluan analisis.

5)Tersedia mekanisme pelaporan internal dan eksternal berkaitan dengan insiden,

6)Tersedia mekanisme untuk menangani berbagai jenis insiden

7)Terdapat kolaborasi dan komunikasi terbuka secara sukarela antar unit dan antar pengelola pelayanan

8)Tersedia sumber daya dan sistem informasi yang dibutuhkan
9)Tersedia sasaran terukur, dan pengumpulan informasi menggunakan kriteria objektif untuk mengevaluasi efektivitas perbaikan kinerja rumah sakit dan keselamatan pasien

6. Mendidik staf tentang keselamatan pasien

Standarnya adalah :

1)RS memiliki proses pendidikan, pelatihan \& orientasi untuk setiap jabatan mencakup keterkaitan jabatan dengan KP secara jelas.

2)RS menyelenggarakan pendidikan \& pelatihan yang berkelanjutan untuk meningkatkan \& memelihara kompetensi staf serta mendukung pendekatan interdisiplin dalam pelayanan pasien.

\section{Kriterianya :}

1)memiliki program diklat dan orientasi bagi staf baru yang memuat topik keselamatan pasien

2)mengintegrasikan topik keselamatan pasien dalam setiap kegiatan inservice training dan memberi pedoman yang jelas tentang pelaporan insiden.

3)menyelenggarakan pelatihan tentang kerjasama kelompok (teamwork) guna mendukung pendekatan interdisiplin dan kolaboratif dalam rangka melayani pasien. 
7.Komunikasi merupakan kunci bagi staf untuk mencapai keselamatan pasien. Standarnya adalah :

1)RS merencanakan \& mendesain proses manajemen informasi KP untuk memenuhi kebutuhan informasi internal \& eksternal.

2)Transmisi data $\&$ informasi harus tepat waktu \& akurat.

\section{Kriterianya :}

1)disediakan anggaran untuk merencanakan dan mendesain proses manajemen untuk memperoleh data dan informasi tentang hal-hal terkait dengan keselamatan pasien.

2)Tersedia mekanisme identifikasi masalah dan kendala komunikasi untuk merevisi manajemen informasi yang ada

Suatu model akan berdampak positif dan baik bila dikembangkan berdasarkan kebutuhan pemberi dan pengguna pelayanan kesehatan khususnya dalam hal ini adalah profesi tenaga perawat anak dan keluarga.Hal ini sesuai dengan konsep pemberdayaan dalam familycentered nursing yang menjelaskan bahwa keluarga memiliki hak dan kewenangan untuk merawat anak anaknya.Maka dari itu salah satu pendekatan pelayanan dalam keperawatan adalah berpusat pada keluarga (family-centereed nursing). Friedman dkk, (2003) berpendapat bahwa family-centred nursing adalah kemampuan perawat memberikan asuhan keperawatan keluarga, sehingga memandirikan anggota keluarga agar tercapai peningkatan kesehatan seluruh anggota keluarganya dan keluarga mampu mengatasi masalah kesehatan (family centered/ berorientasi pada keluarga) (Allender dan Spradley, 2005). Penerapan model pemberdayaan berbasis keluarga : family-centered nursing merupakan teori keperawatan dengan asuhan keperawatan dengan pendekatan proses keperawatan dengan sistem keperawatan pendidikan kesehatan, coaching dan peereducation. Merupakan salah satu intervensi keperawatan yang mendukung pelaksanaan tugas kesehatan keluarga dalam pencegahan penularan penyakit menular. Hal di atas sejalan dengan hasil penelitian yang dilakukan Sjattar, Elly, Burhanuddin, dan Siti (2011) membuktikan bahwa penerapan model keluarga untuk keluarga yang merupakan integrasi dari konsep model dan teori keperawatan Self Care dan FamilyCentered Nursing (SCFCN) dengan cara edukasi suportif pada keluarga yang dilakukan sebanyak tiga kali pertemuan selama tiga minggu sangat berpengaruh terhadap kemandirian keluarga merawat anggota keluarga yang menderita tuberkulosis yang ditandai adanya peningkatan pengetahuan dan kemandirian keluarga pada saat post test. 
Berbagai teori yang menjelaskan peranan keluarga dalam mendukung upaya pencegahan penyakit rabies (Hutapea, 2005) sebagai berikut: (1) Kepatuhan berobat sangat dipengaruhi oleh perilaku penderita; (2) Metode untuk mengubah perilaku masyarakat melalui penyampaian informasi, diskusi, dan peran serta pasien; dan (3) Agar perilaku penderita lebih patuh dibutuhkan memperkuat keinginan dengan melalui persuasi dan penyampaian informasi. Dukungan keluarga dalam upaya pencegahan penyakit rabies dapat dilakukan melalui pemberian informasi, komunikasi, dan dukungan untuk melakukan pencegahan sehingga anggota keluarga memiliki tanggung jawab untuk melakukannya. Bentuk-bentuk dukungan keluarga yang diberikan kepada anggota keluarganya (1) dukungan informasi dari keluarga berfungsi sebagai sebuah pengumpul dan penyebar informasi tentang berbagai persoalan, (2) dukungan assesment yakni keluarga sebagai sebuah bimbingan bersifat respek, menjadi contoh dan menangani pemecahan masalah, (3) dukungan instrumental yaitu keluarga merupakan sebuah sumber pertolongan praktis dan kongkrit, (4) dorongan seperasaan yaitu keluarga menjadi wadah yang menyenangkan (Mullaney, 2013). Kegiatan pencegahan penyakit rabies dapat dilakukan oleh setiap keluarga, bilamana semua anggota keluarga memberikan dukungan untuk melaksanakan kegiatan tersebut melalui wujud dukungan keluarga. Menurut Bomer (Sari, Dewi and Utami, 2012) dukungan keluarga adalah bentuk perilaku melayani yang dilakukan oleh keluarga, baik dalam bentuk dukungan emosional (perhatian, kasih sayang, empati), dukungan penghargaan (menghargai, umpan balik), dukungan informasi (saran, nasehat, informasi) maupun dalam bentuk dukungan instrumental (bantuan tenaga, dana, dan waktu).Perhatian dan empati terhadap stressor dan penggobatan yang dijalani pasien akan membuat seseorang merasa lebih dihargai dan memepengaruhi tingkah laku,meningkatkan kesejahteraan psikologis,serta dapat menggurangi konsekuensi negatif dari stress yang dapat meningkatkan prevalensi kekambuhan penyakit menular.

\section{PENUTUP}

Program keselamatan pasien pada pencegahan KTD berguna untuk mengurangi tingkat kecacatan atau kesalahan dalam memberikan pelayanan kepada pasien di rumah sakit.Untuk dapat menjalankan visi dan misi rumah sakit maka diperlukan kerja sama antar peran yang ikut ambil bagian dalam pelayanan kesehatan.Salah satunya ialah peran keluarga.Peran keluarga dalam 
memberikan

dukungan

emosional,penghargaan,informasi dan

instrumental sangat penting guna

memberikan rasa lebih dihargai dan

memepengaruhi

tingkah

laku,meningkatkan

kesejahteraan

psikologis,serta dapat menggurangi

konsekuensi negatif dari stress yang dapat meningkatkan prevalensi kekambuhan penyakit menular pada pasien.Menurunnya prevalensi kekambuhan dapat mempercepat penyembuhan dan memutus rantai penularan penyakit.

\section{DAFTAR PUSTAKA}

Budiono S, Sarwiyata TW, Alamsyah A. Pelaksanaan Program Manajemen Pasien dengan Risiko Jatuh di Rumah Sakit. J Kedokt Brawijaya. 2014 Aug 3;28(1):7883.

Erlinda,Vitria.(2015). Penerapan Model Family-Centered Nursing Terhadap Pelaksanaan Tugas Kesehatan Keluarga Dalam Pencegahan ISPA Pada Balita Di Wilayah Kerja Puskesmas Simpang Tiga Kabupaten Aceh Besar.Jurnal Kedokteran YARSI 23.(2).168-177.

Firmansyah,Roni Suhanda,Mamat Lukman\&Citra Wandani.(2017). FaktorFaktor yang Berhubungan dengan Dukungan Keluarga dalam Pencegahan Primer Hipertensi.JKP.5(2).199-200
Handayani,Siska Dwi,Cecep Elly Kosasih\&Ayu Prawesti Priambodo.(2017). Evaluasi Penerapan Pencegahan Pasien Berisiko Jatuh di Rumah Sakit.Jurnal Fakultas Ilmu Keperawatan Universitas Padjajaran.2(3).6-10.

Hutapea, T. P. (2015) 'Pengaruh Dukungan Keluarga terhadap Kepatuhan Minum Obat Anti Tuberkulosis', Pengaruh Dukungan Keluarga terhadap Kepatuhan Minum Obat Anti Tuberkulosis, (Tuberkulosis), pp. 1-11. doi: 10.1300/J044v09n04.

Irwan.(2017).EPIDEMOLOGI

PENYAKIT MENULAR. Yogyakarta. CV. ABSOLUTE MEDIA.

Istiawan,Rochani,Junaiti Sahar,\&Adang Bachtiar.(2014). Hubungan Peran Pengawas Minum Obat Oleh Keluarga Dan Petugas Kesehatan Terhadap Pengetahuan, Perilaku Pencegahan Dan Kepatuhan Klien Tbc Dalam Konteks Keperawatan Komunitas Di Kabupaten Wonosobo.Jurnal Keperawatan Soedirman.1(2).98-101.

Juliansyah,Elvi\&Febrian Nurdin.(2019). Faktor Pelayanan Kesehatan, Dukungan Keluarga dan Masyarakat Dengan Upaya Pencegahan Kejadian Rabies di Wilayah Kerja Puskesmas Pandan Kecamatan Sungai Tebelian Kabupaten Sintang.Visikes 
: Jurnal Kesehatan Masyarakat.18(2).123-

126

Kamil,Hajjul.(2015).Patient Safety.Idea

Nursing Journal.1(1).1-4

Nurlaily,Ari Pebru.(2017). Literature

Review: Hubungan Komitmen Organisasi

Terhadap Kinerja Pada Pencegahan

Kejadian Tidak Diharapkan (Ktd). Adi

Husada Nursing Journal.3(1).93-95

Sanjaya,Punguh Danu.(2017).Evaluasi

Penerapan Pencegahan Pasien Berisiko

Jatuh di Rumah Sakit.Jurnal Fakultas

Kesehatan Masyarakat.11(2).105-106

Simamora,R.H.(2019).Buku Ajar

Pelaksanaan Identifikasi Pasien.Uwais

Inspirasi Indonesia. 